Note

\title{
Clostridium difficile from food and surface samples in a Belgian nursing home: An unlikely source of contamination
}

\author{
C. Rodriguez ${ }^{\text {a, }}{ }^{*}$, N. Korsak ${ }^{\text {a }}$, B. Taminiau ${ }^{\text {a }}$, V. Avesani ${ }^{\text {b }}$, J. Van Broeck ${ }^{\text {b }}$, P. Brach ${ }^{\text {c }}$, \\ M. Delmée ${ }^{\mathrm{b}}, \mathrm{G}$. Daube ${ }^{\mathrm{a}}$ \\ a Food Science Department, FARAH, Faculty of Veterinary Medicine, University of Liège, Liège, Belgium \\ ${ }^{\mathrm{b}}$ Microbiology Unit, Catholic University of Louvain, Brussels, Belgium \\ ${ }^{\mathrm{c}}$ Nursing Home Saint-Joséphine site de la Chaussé, ACIS, Theux, Belgium
}

\section{A R T I C L E I N F O}

\section{Article history:}

Received 18 March 2014

Received in revised form

29 December 2014

Accepted 4 January 2015

Available online 5 January 2015

\begin{abstract}
A B S T R A C T
This study investigates the contamination of foods and surfaces with Clostridium difficile in a single nursing home. C. difficile PCR-ribotype 078 was found in one food sample and in none of the tested surfaces. These results indicate that food and surfaces are an unlikely source of $C$. difficile infection in this setting.
\end{abstract}

(C) 2015 Published by Elsevier Ltd.

Keywords:

Clostridium difficile

Food

Surfaces

Nursing-home

Clostridium difficile is a spore-forming anaerobic bacterium recognised as a major cause of nosocomial colitis and antibiotic associated diarrhoea. The main risk factors for $C$. difficile infection (CDI) are considered to be patient age over 65 years; gut microbiota changes; previous hospitalization; antibiotic exposure and certain underlying diseases $[1,2]$. Nursing homes can therefore be particularly susceptible to outbreaks [3], and the environment (e.g. contaminated surfaces in resident rooms) and foods might play a significant role in the nosocomial transmission of this bacterium $[4,5]$.

The aim of this study was to assess the presence of $C$. difficile on freshly prepared food in the kitchen area of a nursing home and to examine the presence of this bacterium in the environment, including kitchen surfaces, patient rooms, toilets and common lounges of the retirement home.

The study was conducted over four months, from March to June 2013, at a local Belgian nursing home with a total capacity of 110 beds. This healthcare facility implemented cleaning protocols to assure an appropriate eradication of $C$. difficile spores. Residents'

\footnotetext{
* Corresponding author. Food Science Department, Faculty of Veterinary Medicine, University of Liège, B43bis, Sart-Tilman, 4000 Liège, Belgium.

E-mail address: c.rodriguez@ulg.ac.be (C. Rodriguez).
}

rooms are cleaned and disinfected daily using bleach-based disinfectants (sodium hypochlorite 10\%). Subsequent automated gaseous decontamination (stabilised hydrogen peroxide 6\%) is also performed weekly. However, for residents suffering from CDI, the automated gaseous decontamination of the room is performed every day.

During the study period, one case of CDI was diagnosed by the nursing home medical services between weeks 11 and 14 while an additional case was detected 9 days before the study began. Furthermore, during the same study period another research work was conducted in the same nursing home. A group of 23 elderlycare home residents was followed weekly to evaluate the presence of $C$. difficile. Preliminary results revealed 7 out of $23 \mathrm{moni}-$ tored residents positives for $C$. difficile at least once. Regarding positive residents to the bacterium, $57.1 \%$ ( 4 out of 7 ) suffered at least one diarrhoea episode at the time of sample collection. However, the nursing home did not experience a $C$. difficile outbreak during the study period. The main $C$. difficile strains found in the nursing home residents were identified as PCR-ribotypes 027, UCL36 and UCL16a (unpublished data). UCL followed by an international number was used only for $C$. difficile strains that presented a PCR-ribotype profile which not matched the Cardiff ribotypes from the strain collection available in our laboratory. None of the human strains isolated during the entire study were 
identified as PCR-ribotype 078.

In this nursing home, all meals for residents served daily in the canteen are prepared in-house by the kitchen staff. A second kitchen is available for residents who want to prepare their own meals. Every day (where possible), approximately $90 \mathrm{~g}$ of the main course of the midday meal prepared in the canteen and $60 \mathrm{~g}$ from a meal prepared in the resident's kitchen were sampled and stored at $-20{ }^{\circ} \mathrm{C}$ in the nursing home's freezer for a maximum of 6 days. This meal quantity was the maximum provided by the two kitchen's services of the nursing home and included all food sorts of the meal in equal parts. Every Friday, samples were collected and transported to the laboratory for immediate analysis. The food preparation date, analysis date, quantity, and ingredients for each sample were recorded.

Samples from surfaces were taken on two different occasions with a 65-day interval between them (5th March and 8th May). A variety of areas in the canteen kitchen (including trays and meal delivery carts for the canteen and rooms) kitchen-staff locker room and bathroom, residents' rooms, private bathrooms, residence hall, lifts and staircase railings were tested. Samples from common areas, the kitchen and the staff bathroom and locker room were swabbed after routine cleaning. Resident rooms were sampled before $(n=4)$ or after $(n=4)$ being cleaned. A variety of residents' rooms were sampled, covering a range of occupancy and need requirements; private rooms were sampled from dependant, semidependant and independent residents. The dependant classification was used for residents who were confined to bed. Residents able to get out of bed but who need assistance with walking, toileting or eating in the canteen were classified as semi-dependant. Independent residents were identified as those who can perform all basic tasks necessary for a normal life without additional care support. On the first day of sampling, surface swabs were collected from randomly chosen rooms. During the second visit, sampling was performed in rooms from residents previously tested and identified as positive for $C$. difficile, based on the previous results of faeces culture (Table 1). Samples were collected using a sterile cotton swab first moistened in sterile buffered peptone water with cysteine $0.5 \%$ (Oxoid, Dardilly, France). A total area of approximately $100 \mathrm{~cm}^{2}$ was swabbed for each sample. Swabs were placed in sterile and labelled $10 \mathrm{ml}$ tubes. They were kept at room temperature for a maximum of $5 \mathrm{~h}$ until arrival at the laboratory, where they were immediately processed.

An enrichment culture was performed on all samples. A total of $50 \mathrm{~g}$ of meal was added to $150 \mathrm{ml}$ of cycloserine cefoxitin fructose taurocholate (CCFT) broth (produced in-house), as previously described [6] but without agar, and both were homogenized $3 \mathrm{~min}$ in a stomacher device (Interscience, Saint-Nom-La Brechete, France). Surface swabs were placed into $10 \mathrm{ml}$ of CCFT. The enrichment broth was incubated for 3 days in the case of food samples and for 10 days in the case of surface samples, both at $37{ }^{\circ} \mathrm{C}$ in an anaerobic workstation (Led Techno, Heusden-Zolder, Belgium). Subsequently, approximately $10 \mu \mathrm{l}$ of the broth was spread on to CCFT plates [6] and incubated anaerobically for $48 \mathrm{~h}$ at $37{ }^{\circ} \mathrm{C}$. Suspected colonies were identified by $\mathrm{C}$. difficile latex agglutination rapid test Kit DR 1107A (Oxoid) and by C. difficilespecific PCR, as previously described [7]. A cytotoxicity assay using MRC-5 cells was performed, as described elsewhere [8].

C. difficile isolates were characterised using the GenotypeCDiff test system (HainLifescience, Nehren, Germany) for detection of all toxin genes ( $t c d A, t c d B, c d t A$ and $c d t B$ ), the deletions in the regulator gene $t c d C$ ( $18 \mathrm{bp}$ and $39 \mathrm{bp}$ deletions or single base deletion at position 117), and gyrA mutation, according to the manufacturer's instructions. PCR-ribotyping was performed as described previously [9].

A total of 246 environmental surfaces and 188 food samples were analysed. $C$. difficile was isolated from only one meal sample $(0.53 \%)$ composed of pork sausage, mustard sauce and carrot salad. This meal had been prepared in the canteen kitchen. The isolate had a toxic activity confirmed by cytotoxicity assay and contained the genes coding for the A, B and binary toxin. A 39 bp deletion in the regulator gene $t c d C$ was also detected. The isolate was identified as PCR-ribotype 078.

This finding suggest that the contamination level in prepared meals is lower than the contamination reported in other raw foods such as meat or vegetables where the prevalence ranged between $0.9 \%$ and $20 \%$ [10]. Regarding the prevalence of $C$. difficile in foods in Belgium, only one previous study reported the presence of the bacterium in retail meat with a percentage of positive samples ranging between $2.3 \%$ and $4.7 \%$ [11]. One possible explanation for this low recovery rate in prepared meals is that an inhibitory effect on C. difficile spores has been observed after a heat shock at $85{ }^{\circ} \mathrm{C}$, with a sub-lethal effect at $71^{\circ} \mathrm{C}[12]$. In this study, a total of 70 out of 188 (70.7\%) samples analysed were composed entirely from cooked ingredients, while 55 out of 188 (29.3\%) contained one or more raw ingredients such as lettuce, tomato or raw meat. The only positive sample for $C$. difficile was recovered from a meal composed of carrot salad, mustard sauce and pork sausage. However, contamination could have originated from any of the ingredients (as they were analysed together) or even from the kitchener's hands. The PCRribotype isolated (078) has been frequently reported in pork retail meat in USA and Canada [10] but has also been considered as an emergent hypervirulent strain in humans [13]. Nevertheless, in the present study none of the circulating clinical $C$. difficile isolates in the nursing home were identified as PCR-ribotype 078. These results indicate that food is an unlikely source of $C$. difficile infection in the nursing home evaluated.

Surprisingly, none of the surfaces sampled were positive for C. difficile, even after 10 enrichment days on selective medium.

Table 1

Characteristics of the resident's rooms sampled.

\begin{tabular}{|c|c|c|c|c|}
\hline Room identification & Floor & Resident health condition & $\begin{array}{l}\text { Sampling before or after } \\
\text { cleaning room routine }\end{array}$ & Resident faeces analysis for $C$. difficile \\
\hline 0 & 1 & Semi-independent resident & Sampling before being cleaned & Not tested \\
\hline A & 1 & Independent resident & Sampling after being cleaned & Not tested \\
\hline $\mathrm{B}$ & 1 & Dependent resident & Sampling after being cleaned & Not tested \\
\hline $\mathrm{C}$ & 2 & Independent resident & Sampling before being cleaned & Not tested \\
\hline $\mathrm{D}$ & 2 & Dependent resident & Sampling after being cleaned & Positive $^{\mathrm{a}}$ \\
\hline $\mathrm{E}$ & 2 & Independent resident & Sampling before being cleaned & Positive $^{a}$ \\
\hline $\mathrm{F}$ & 3 & Independent resident & Sampling before being cleaned & Positive $^{c}$ \\
\hline G & 3 & Dependent resident & Sampling after being cleaned & Positive $^{\mathrm{b}}$ \\
\hline
\end{tabular}

a Resident positive for $C$. difficile at least one week before and at the time of sampling.

b Resident positive for $C$. difficile one week before sampling.

c Resident positive for $C$. difficile two weeks before sampling. 
Previous studies have reported an environmental contamination of C. difficile spores in hospitals with a prevalence ranging between $2.4 \%$ and $47 \%$ [14-17]. A range of culture methods have been proposed to isolate environmental C. difficile, including swabbing [14], electrostatic cloths [15] contact CCFT plates [16] and rodac plates [17]. This diversity in the methodology can help to explain the variations in spore detection. For this reason, a standard method to estimate the environmental contamination of $C$. difficile spores would be desirable. However, care was taken to achieve robust results: a large number of samples were performed from a variety of surface types, including the zones commonly contaminated, e.g. bedside table, bedrail or toilet floor [14]; sampling was performed on two different days separated by a large time interval (65 days); and an effort was made to exert the maximum pressure possible for each swab. Because of these measures, our results indicate that the implemented clean program to control the spread of $C$. difficile on the nursing home is effective and if there was any surface contamination, the number of spores in the environment must have been very low and not easy detectable.

In conclusion, the results of this study indicate that the nursing home environment and meals studied are unlikely to serve as vector of $C$. difficile infection. As meals from two different kitchens with different hygiene procedures were tested over a period of four months, we report a low $C$. difficile contamination level in ready-toeat foods prepared in the nursing home's kitchens. For the environment, it is probable that results vary significantly between retirement and healthcare establishments according to procedures for routine cleaning and disinfecting, or even depending on the procedure used to isolate $C$. difficile.

\section{Acknowledgements}

The authors wish to thank the nursing home Saint-Joséphine for participating in this study and Eng. Alberto Rufi for technical support. Our most sincere thanks to Phyllis Smith and Catherine Painter for their support in editing the manuscript.

\section{References}

[1] G. Dulny, M. Zalewska, G. Mlynarczyk, An analysis of risk factors of Clostridium difficile infection in patients hospitalized in the teaching hospital in 2008, Prz. Epidemiol. 63 (2013) 445-450, 547-51.
[2] J.M. Wenish, D. Schmid, H.W. Kuo, E. Simons, F. Allerberger, V. Michl, et al., Hospital-acquired Clostridium difficile infection: determinants for severe disease, Eur. J. Clin. Microbiol. Infect. Dis. 31 (2012) 1923-1930.

[3] M. Arvand, V. Moser, C. Schwehn, G. Bettge-Weller, M.P. Hensgens, EdJ. Kuijper, High prevalence of Clostridium difficile colonization among nursing home residents in Hesse, Germany, PLoS One 7 (2012) e30183.

[4] C.D. Faires, D.L. Pearl, O. Berke, R.J. Reid-Smith, J.S. Weese, The identification and epidemiology of methicillin-resistant Staphylococcus aureus and Clostridium difficile in patient rooms and the ward environment, BMC Infect. Dis. $13(2013) 342$.

[5] D.G. Hoover, A. Rodriguez-Palacios, Transmission of Clostridium difficile in foods, Infect. Dis. Clin. N. Am. 27 (2013) 675-685.

[6] M. Delmée, B. Vandercam, V. Avesani, J.L. Michaux, Epidemiology and prevention of Clostridium difficile infections in a leukaemia unit, Eur. J. Clin. Microbiol. 6 (1987) 623-627.

[7] C. Rodriguez, V. Avesani, J. Van Broeck, B. Taminiau, M. Delmée, G. Daube, Presence of Clostridium difficile in pigs and cattle intestinal contents and carcass contamination at the slaughterhouse in Belgium, Int. J. Food Microbiol. 2 (2013) 256-262.

[8] C. Rodriguez, B. Taminiau, J. Van Broeck, V. Avesani, M. Delmée, G. Daube, Clostridium difficile in young farm animals ans slaughter animals in Belgium, Anaerobe 18 (2012) 621-625.

[9] P. Bidet, F. Barbut, V. Lalande, B. Burghoffer, J.C. Petit, Development of a new PCR-ribotyping method base on ribosomal RNA gene sequencing, FEMS Microbiol. Lett. 175 (1999) 261-266.

[10] M.P.M. Hensgens, E.C. Keessen, M.M. Squire, T.V. Riley, M.G.J. Koene, E. De Boer, L.J.A. Lipman, E.J. Kuijper, European Society of Clinical Microbiology and Infectious Diseases Study Group for Clostridium difficile (ESGCD). Clostridium difficile infection in the community: a zoonotic disease? Clin. Microbiol. Infect. Dis. 18 (2012) 635-645.

[11] C. Rodriguez, B. Taminiau, V. Avesani, J. Van Broeck, M. Delmée, G. Daube, Multilocus sequence typing analysis and antibiotic resistance of Clostridium difficile strains isolated from retail meat and humans in Belgium, Food Microbiol. 42 (2014) 166-171.

[12] A. Rodriguez-Palacios, J.T. LeJeune, Moist-heat resistance, spore aging, and superdormancy in Clostridium difficile, Appl. Environ. Microbiol. 77 (2011) 3085-3091.

[13] A. Goorhuis, D. Bakker, J. Corver, S.B. Debast, C. Haemanus, D.W. Notermans, et al., Emergence of Clostridium difficile infection due to a new hypervirulent strain, polymerase chain reaction ribotype 078, Clin. Infect. Dis. 47 (2008) $1162-1170$.

[14] M. Sjörberg, M. Eriksson, J. Andersson, T. Noren, Transmission of Clostridium difficile spores in isolation room environments and through hospital beds, APMIS 122 (2013) 800-803.

[15] A. Kramer, I. Schwebke, G. Kampf, How long do nosocomial pathogens persist on inanimate surfaces? A systematic review, BMC Infect. Dis. 6 (2006) 130.

[16] J.S. Weese, H.R. Staempfli, J.F. Prescott, Isolation of environmental Clostridium difficile from a veterinary teaching hospital, J. Vet. Diagn Investig. 12 (2000) 449-452.

[17] K.H. Kim, R. Fekety, D.H. Batts, D. Brown, M. Cudmore, J. Silva Jr., D. Waters, Isolation of Clostridium difficile from the environment and contacts of patients with antibiotic-induced colitis, J. Infect. Dis. 143 (1981) 42-50. 